\title{
Study on the Cumulative Innovation Effect of the Competitive Patent Pools Based on the Different Technical Standards
}

\author{
Youtao Luo ${ }^{*}$, Zheng Liang ${ }^{1}$ Xiaojun $\mathrm{Du}^{2}$, Dong Xia ${ }^{2}$ \\ ${ }^{1}$ The School of Public Policy and Management, Tsinghua University, Beijing, China \\ ${ }^{2}$ The School of Business Administration, Northeastern University, Shenyang, China \\ Email: *youtaoluo99@163.com
}

Received 19 April 2016; accepted 2 July 2016; published 5 July 2016

Copyright (C) 2016 by authors and Scientific Research Publishing Inc.

This work is licensed under the Creative Commons Attribution International License (CC BY).

http://creativecommons.org/licenses/by/4.0/

c) (†) Open Access

\begin{abstract}
Multi-patent pools based on different technical standards are appearing in many technique industries with competitions becoming intensive among technical standards. Theoretical model of cumulative innovation effect of competitive patent pools based on different technical standards is developed by dynamic game theory in this paper to study the cumulative innovation effect of competitive patent pool under the different patent types of relationship between patents, which are blocking patent, substitutability patent and additional innovation patent. This research indicates: the $R \& D$ investments of an enterprise inside a patent pool increase (or decrease) as the $R \& D$ investments of other enterprises inside the same patent pool decrease (or increase) or as the R\&D investments of the enterprises inside another patent pool or the R\&D investments of the enterprises outside patent pools increase (or decrease) during the patent race of blocking patent. The bigger differentiation degree between patents is, the $R \& D$ investments of all enterprises are more during the patent race of substitutability patent. The R\&D investments of an enterprise inside a patent pool are bigger than outside the patent pools during the patent race of additional innovation patent.
\end{abstract}

\section{Keywords}

Different Technical Standards, Competitive Patent Pools, R \& D Investments, Patent Race, Type of Patent

\footnotetext{
"Corresponding author.

How to cite this paper: Luo, Y.T., Liang, Z., Du, X.J. and Xia, D. (2016) Study on the Cumulative Innovation Effect of the Competitive Patent Pools Based on the Different Technical Standards. Open Journal of Business and Management, 4, 445460. http://dx.doi.org/10.4236/ojbm.2016.43046
} 


\section{Introduction}

A patent pool is an agreement among patent owners to license a set of their patents to one another or to third parties. Patent pool have played an important role in industry since the 1856 sewing machine pool (Josh Lerner, Jean Tirole, 2004) [1]. Because a patent pool is a natural and effective method used by market participants to cut through the patent thickets (Shapiro, 2001) [2] and the patent pool has a "isolated function" that can prevent competitors to imitate and copy core technology, a patent pool has advantage in high and new technology industries (Deepak, David, 2001) [3]. With the development of the integration of world economy and the intensifying of international competition, patent pool whose main body is enterprise is a paradigm of industry competition especially in electronic, information technology, communication technology, biological pharmacy, and so on, high and new technology industries. However Brenner S. (2009) [4] found out "coalition dilemma" of patent pool, patent pool was not complete, namely patent pool did not include all essential patents that were applied in A technology or $A$ technical standard. Meanwhile because of competition among technical standards, there form multiple competitive patent pool based on different technical standards in one industry. For 3G communication technology industry, there are four competitive patent pools based on four types of technical standard, which are CDMA2000, WCDMA, TD-SCDMA, WiMAX. Therefore it is considerable realistic significance to study competitive patent pool based on multi-technical standards.

We developed a mathematical model of double competitive patent pool based on different technical standards to study on innovation effect of patent pool with dynamic game theory in this paper.

\section{Literature Review}

Sharpiro (2001) [2] made use of Cournot model to analyse the formation of patent pool. Kim (2004) [5] introduced patent type and Market linear demand function of terminal products into study on economic efficiency of patent pool, and came to a conclusion that patent pool are efficient in products production. Schmidt (2008) [6] applied blocking patent in analysis of patent pool and systematically studied on patent innovation under different situations that are market without patent pool, vertical integration market with patent pool and horizontal integration market with patent pool. On the term of innovation, he believes vertical integration market hinders and reduces innovation motivation, while horizontal integration market is to facilitate innovation. Kato (2004) [7] discussed patent pool that have alternative patents. Brenner (2004) [8] researched on incomplete patent pool. This research considered some influence of formation of patent pool brought by the firms of research and development of patent outside patent pool.

Although above researches do not involve innovation effect of competitive patent pool, they are groundwork. In this paper, we will apply many methods and assumptions form them.

At present, academic researches on patent pool concentrated in monopoly and formation of patent pool, yet lack of innovation effect of patent pool. Significant theoretical researches on innovation effect of patent pool are as follows:

Denicolo (2000) [9] developed the model of two-stage patent race and Denicolo (2002) [10] structured the model of cumulative innovation. These models both discussed the change of firms' investments in product patent to production at different patent-race stages.

Hunt (2003) [11] used Cournot model to analyse that the relationship between the number of patents owned by firms and firms' research and development (R\&D) investments, and then he believe that firms' R\&D investments and the number of patents owned by firms is negative correlation when expected profit is low, R\&D investments is excessive and function of existing patents overlap patents to be developed in an industry.

Dequiedt and Versaevel (2007) [12] studied that the change of firms’ R\&D investments at before the formation of patent pool and after that. They found that at the beginning of formation of patent pool on R\&D intensity has a positive effect overall. Before the formation of patent pool, the R\&D investments will gradually increase, while after the formation of patent pool, stimulating will disappear, acquire not the R\&D investments of firms don't acquire patents will fall down to the no-pool of the same level. As the patent pool with smaller size reduces time discounting pro-formation of pool, and make bigger opportunity cost every time patent race. So the patent pool with smaller size produces bigger stimulating of innovation. Perhaps it generate two kinds of inefficient fault, one is over investments then deviating the patentee' holistic profit maximization, the other that originator who prepares to set up patent pool will put off building pool, result in oversize of pool then deviating optimum social welfare. 
After analysed and summarized existing researches on innovation effect of patent pool, we can find existing researches all have assumptions that are an industry only has one patent pool and blocking patents, therefore existing researches have defects that are as follows: (i) lack of research on innovation effect of multi-pool; (ii) they do not introduce different types of patent into research on innovation effect of patent pool; (iii) they do not consider what enterprise cluster of patent R\&D outside patent pools impact on innovation of patent pools.

Based on the above reasons, we introduce some vital factors, for example different types of patent and enterprise cluster of patent R\&D outside patent pools etc. into research on innovation effect of multi-pool, and develop a mathematical model of two-stage dynamic game with the help of applying the backward induction under patent pool's established regulations. In this paper, we will study on innovation effect of double competitive patent pools in order to complete theoretical research on patent pools.

\section{Concept Definition and Model Assumption}

\subsection{Concept Definition}

1) Innovation Effect

In this paper, innovation effect is that the fund of $R \& D$ investment in new patents is influenced by patent pools. The firms of R\&D new patents may be either inside or outside pools.

2) Cumulative Innovation

Cumulative innovation is that any new production of patents is based on the old patents, namely function of the old patents was mended and transformed. In this paper, cumulative innovation is specifically defined that any new patents are produced in upstream-market or terminal products in the downstream-market must be applied patents owned by the patent pools in upstream-market.

3) The Type of Patent

In this paper, the type of patent is that the relationship between new and old patents, and this relationship is composed of three relations that are blocking patents, improvement patents and additional innovation patents. These three types of patent are classified by Gilbert, R. (2004) [13].

Blocking patents are also named complementary patents. Blocking patents are that patents $A$ and $B$ are in a blocking relationship if the practice of each patent would infringe the other in the absence of a license. In other words, patents if the practice of $B$ (or $A$ ) requires a license from $A$ (or $B$ ). This typically corresponds to a situation where $B$ improves $A$ in some capacity (or $A$ may cover a research tool or some other process that is necessary to produce a product covered by $B$ ).

Improvement patents are able to enhance terminal product differentiation when improvement patents and patents in a patent pool are united to use. Improvement patents and patents in a patent pool are complementary for each other, so they can be recruited in a pool. In order to clarify this relationship, suppose there are two patent pool $A$ and patent pool $B$ in one industry, if pool $A$ gets a improvement patent, this improvement patent is complementary for the other patents in pool $A$, ant it can enhance differentiation between pool $A$ and pool $\mathrm{B}$, consequently pool $A$ has bigger competitive advantage for pool $B$. At this case, we call pool $A$ advanced pool but pool $B$ is non-advanced pool.

Additional innovation patents can be independently applied in products production to lower the production cost and ameliorate terminal product, in a word they can bring additional value for firms. Additional innovation patents do not belong to complementary patents for pool $A$ and pool $B$, so they are not restrained by Grant-back Clause and they are not recruited in pools.

\subsection{Model Assumption}

At first, we assume that an industry is composed of two markets, one is a market of patents R\&D and patents license, and this market is in upstream, certainly we call it upstream-market. The other is a market of terminal products sales and production, and this market is in downstream, then we call it downstream-market.

There are two patent pools and enterprise cluster in upstream-market. These two patent pools have competitiveness, in other words, products have substitutability that are respectively made by patents from different pools. We use corner mark $A$ to indicate all variables related to one pool, corner mark $B$ indicate all variables related to the other pool and corner mark $C$ indicate all variables related to enterprise cluster. The enterprise cluster also research and develop patent but it is outside two patent pools. We called it firms outside pools. 
Upstream-market makes a profit from R\&D new patents and patent license, the fee of patent license is $l$. There are $n$ homogeneous firms to produce terminal products for customers in downstream-market. These firms in downstream-market need pay for the fee of patent license to acquire the right to the use of patent to produce terminal products. The terminal products, need use patents owned by pools to be made, are different but have substitutability from patents owned different pools. In order to distinguish these terminal products and convenient for analysis, we still use corner mark $A$ to indicate all variable related to the terminal products that are produce by means of patents from pool $A$, on other side we use corner mark $B$ to indicate all variable related to the terminal products that are produce by means of patents from pool $B$.

We further assume as follows:

Assumption 1. The type of patents in pool is complementary (namely, blocking). Today most of countries provide that the patents in the pool should be complementary patents (or called blocking patents).

According to Lerner \& Tirole’s researches [1], assumption 1 can stop patent pool becoming monopoly, and also stop substitutability patents entering into the same pool, sequentially increase probability of competitive patent pools' forming.

Assumption 2. The fee of patent license is FRAND (Fair, Reasonable and Non discriminatory) and linear.

Because of the characteristic of risk sharing, linear licensing fee is widely used in reality, it is general pricing principle of patent pool. Layne and Lerner (2008) [14] have applied this assumption to research on patent pool.

Assumption 3. A firm's income from licensing fee in patent pool is according to the number of essential patents which are owned by the firm.

Take universal regulation of distribution of profit in patent pool, namely "regulation of quantity of patent". Suppose the gross profit of patent pool $A$ is $\pi$, firm $i$ in patent pool $A$ owns $k_{i}^{A}$ patents, patent pool $A$ has $N^{A}$ firms, then the profit of firm $i$ is $\left(k_{i}^{A} / \sum_{j=1}^{N^{A}} k_{j}^{A}\right) \pi$ in patent pool $A$.

Assumption 4. The market information is complete information.

Upstream firms in pool and downstream firms can both observe action among one another and know all information about products and patents, and then take reasonable strategies for maximizing profit.

Assumption 5. The firms in two pools have symmetrical characteristic. The firms have the same production and cost functions. There are researches on patent pool adopt this assumption.

Assumption 6. The investment of firm's R\&D is a "Poisson Process" of "no memory" of patent race. That is to say, the probability of success of producing new patent during time $t$ is decided by the function $h\left(x_{i}\right)$, yet is not related to experience and past investments. The function $h\left(x_{i}\right)$ is the probability of success that a firm can produce a new patent, $x_{i}$ is the fund that a firm invest for a new patent. That is to say, If R\&D investment of firm $i$ is $x_{i}$ from $t$ to $t+\mathrm{d} t$, in this period, the probability of success of the firm $i$ producing new patent is $h\left(x_{i}\right) \mathrm{d} t \cdot h\left(x_{i}\right)$ is concave, that is:

$$
\begin{aligned}
& h^{\prime}\left(x_{i}\right)>0, h^{\prime \prime}\left(x_{i}\right)<0, h(0)=0 \\
& \lim _{x_{i} \rightarrow 0} h^{\prime}\left(x_{i}\right) \rightarrow \infty, \lim _{x_{i} \rightarrow \infty} h^{\prime}\left(x_{i}\right) \rightarrow 0
\end{aligned}
$$

It is able to insure that unique solution of Markov perfect equilibrium of game exists [11] that $h\left(x_{i}\right)$ is concave.

In industries, firms' behavior of R\&D patents is mutual independence, and in period of time, only one new patent can be successfully R\&D, because of patent right protection, if one firm successfully produce a new patent, the other firms will give up R\&D this patent, namely firms' behavior of R\&D patents is mutual exclusive, therefore we can get $h\left(\sum_{i} x_{i}\right)=\sum_{i} h\left(x_{i}\right)$ because the probability of mutual exclusive events is countable additivity.

This assumption is theoretically brought up by Brandeis and Stiglitz Kubert (1980), Lee and Wilder (1980) [15], Lory (1979) and Tired Reinganum $(1979,1982)$ et al.

Assumption 7. Patent pools all have Grant-back Clause (Lerner and Strojwas, 2007) [16] and firms in pools do not independently license patents. 


\section{Model and Innovation Effect Analysis}

\subsection{Model}

We apply "Cournot competition model” and theory of dynamic game. Game order is as follow:

The first stage: two upstream patent pools set licensing fee simultaneously $l^{A}$ and $l^{B}$.

The second stage: all downstream manufacturers take actions and decide output after observing licensing fee.

The inverse demand function of two types of differentiation products are defined as follow:

$$
\begin{aligned}
& P^{A}=a-b\left(Q^{A}+\theta Q^{B}\right)=a-b\left(\sum_{i=1}^{n} q_{i}^{A}+\theta \sum_{i=1}^{n} q_{i}^{B}\right) \\
& P^{B}=a-b\left(Q^{B}+\theta Q^{A}\right)=a-b\left(\sum_{i=1}^{n} q_{i}^{B}+\theta \sum_{i=1}^{n} q_{i}^{A}\right)
\end{aligned}
$$

Equation (1): $P^{A}$ is the price of product A, $P^{B}$ is the price of product B. $q_{i}^{A}$ is the output of products $A$ that are made by firm $i, q_{i}^{B}$ is the output of products $B$ that are made by downstream manufacturer $i . \quad \theta \in(0,1)$ is the level of differentiation between product $A$ and product $B, \theta$ is closer to 1 , the level of differentiation is lower. In extreme case, $\theta=0$, show product $A$ and product $B$ are completely uncorrelated, namely product $A$ and product $B$ cannot substitute for each other. $\theta=1$, indicate product $A$ and product $B$ are perfect correlation, namely product $A$ and product $B$ can substitute completely for each other.

We suppose $c^{A}$ is the marginal cost of product $A, c^{B}$ is the marginal cost of product $\mathrm{B}$. Then the total marginal cost of product $A$ and product $B$ are as follow:

$$
\begin{aligned}
& C^{A}=l^{A}+c^{A} \\
& C^{B}=l^{B}+c^{B}
\end{aligned}
$$

If downstream manufacturer $i$ make product $A$ and product $B$, it can get profits as follow:

$$
\begin{aligned}
& \pi_{i}\left(q_{i}^{A}, q_{i}^{B}\right)=\left(P^{A}-C^{A}\right) q_{i}^{A}+\left(P^{B}-C^{B}\right) q_{i}^{B} \\
& =\left[a-b\left(\sum_{i=1}^{n} q_{i}^{A}+\theta \sum_{i=1}^{n} q_{i}^{B}\right)-\left(l^{A}+c^{A}\right)\right] q_{i}^{A}+\left[a-b\left(\sum_{i=1}^{n} q_{i}^{B}+\theta \sum_{i=1}^{n} q_{i}^{A}\right)-\left(l^{B}+c^{B}\right)\right] q_{i}^{B}
\end{aligned}
$$

Because of seeking to maximize profit, the first-order condition for maximum profit $\partial \pi_{i} / \partial q_{i}^{A}=0, \partial \pi_{i} / \partial q_{i}^{B}=0$, we have:

$$
\begin{aligned}
& \partial \pi_{i} / \partial q_{i}^{A}=a-b \sum_{i=1}^{n} q_{i}^{A}-b \theta \sum_{i=1}^{n} q_{i}^{B}-l^{A}-c^{A}-b q_{i}^{A}-b \theta q_{i}^{B}=0 \\
& \partial \pi_{i} / \partial q_{i}^{B}=a-b \sum_{i=1}^{n} q_{i}^{B}-b \theta \sum_{i=1}^{n} q_{i}^{A}-l^{B}-c^{B}-b q_{i}^{B}-b \theta q_{i}^{A}=0
\end{aligned}
$$

After we solve Equation (4), we can get:

$$
\begin{aligned}
q_{i}^{A} & =\frac{1}{n+1} \cdot \frac{a(1-\theta)-l^{A}+\theta l^{B}-c^{A}+\theta c^{B}}{b\left(1-\theta^{2}\right)} \\
q_{i}^{B} & =\frac{1}{n+1} \cdot \frac{a(1-\theta)-l^{B}+\theta l^{A}-c^{B}+\theta c^{A}}{b\left(1-\theta^{2}\right)} \\
Q^{A} & =\frac{n}{n+1} \cdot \frac{a(1-\theta)-l^{A}+\theta l^{B}-c^{A}+\theta c^{B}}{b\left(1-\theta^{2}\right)} \\
Q^{B} & =\frac{n}{n+1} \cdot \frac{a(1-\theta)-l^{B}+\theta l^{A}-c^{B}+\theta c^{A}}{b\left(1-\theta^{2}\right)}
\end{aligned}
$$

From above, under different standards, the level of output depends on the licensing fee of product $A$ and product $B$ and the marginal cost of product $A$ and product $B$. we temporarily suppose the marginal cost of prod- 
uct $A$ and product $B$ is all constant. Then we see that upstream patent pools can control the level of output of downstream manufacturers by means of setting the licensing fee.

Because of the cost of licensing is free, the profits of upstream patent pools are as follow:

$$
\begin{aligned}
& \Pi^{A}=l^{A} Q^{A}=l^{A} \cdot \frac{n}{n+1} \cdot \frac{a(1-\theta)-l^{A}+\theta l^{B}-c^{A}+\theta c^{B}}{b\left(1-\theta^{2}\right)} \\
& \Pi^{B}=l^{B} Q^{B}=l^{B} \cdot \frac{n}{n+1} \cdot \frac{a(1-\theta)-l^{B}+\theta l^{A}-c^{B}+\theta c^{A}}{b\left(1-\theta^{2}\right)}
\end{aligned}
$$

The first-order condition for maximum value is $\partial \Pi^{A} / \partial l^{A}=0, \partial \Pi^{B} / \partial l^{B}=0$, we can solve reaction function as follow:

$$
\begin{aligned}
& l^{A}=\frac{a(1-\theta)+\theta l^{B}-c^{A}+\theta c^{B}}{2} \\
& l^{B}=\frac{a(1-\theta)+\theta l^{A}-c^{B}+\theta c^{A}}{2}
\end{aligned}
$$

From Equation (7), we can get:

$$
\begin{aligned}
& l^{A}=\frac{a(2+\theta)(1-\theta)-\left(2-\theta^{2}\right) c^{A}+\theta c^{B}}{4-\theta^{2}} \\
& l^{B}=\frac{a(2+\theta)(1-\theta)-\left(2-\theta^{2}\right) c^{B}+\theta c^{A}}{4-\theta^{2}}
\end{aligned}
$$

By plugging Equation (8) into Equation (6), we can get the profits of upstream patent pools as follow:

$$
\begin{aligned}
& \Pi^{A}=\frac{n}{n+1} \cdot \frac{1}{\left(1-\theta^{2}\right) b} \cdot\left[\frac{a(2+\theta)(1-\theta)-\left(2-\theta^{2}\right) c^{A}+\theta c^{B}}{4-\theta^{2}}\right] \\
& \Pi^{B}=\frac{n}{n+1} \cdot \frac{1}{\left(1-\theta^{2}\right) b} \cdot\left[\frac{a(2+\theta)(1-\theta)-\left(2-\theta^{2}\right) c^{B}+\theta c^{A}}{4-\theta^{2}}\right]
\end{aligned}
$$

As both products are substitutability, we can suppose $c^{A}=c^{B}=c$, then we can rewrite Equation (8) as:

$$
l^{A}=l^{B}=\frac{(a-c)(1-\theta)}{2-\theta}
$$

By plugging Equation (10) into Equation (6), we can get:

$$
\Pi^{A}=\Pi^{B}=\frac{n}{n+1} \cdot \frac{(a-c)^{2}(1-\theta)}{(2-\theta)^{2}(1+\theta) b}
$$

\subsection{Analysis of Innovation Effect of Blocking Patents}

Assume there is a chance to R\&D new blocking patent, pool $A$, pool $B$ and enterprise cluster $C$ outside pools all want to produce this new blocking patent, they all put investment in this patent. We use corner mark $d$ to indicate all variables related to this new blocking patent.

If a firm in enterprise cluster $C$ successfully produces this new blocking patent, it will charge patent license fee $l^{C}$ to the firms in downstream-market. In the light of built model and Formula (4), we can mend the firstorder condition for maximum value of profit that is the firms in the downstream-market, as follows:

$$
\begin{aligned}
& \partial \pi_{i} / \partial q_{i}^{A}=a-b \sum_{i=1}^{n} q_{i}^{A}-b \theta \sum_{i=1}^{n} q_{i}^{B}-l^{A}-l^{C}-c-b q_{i}^{A}-b \theta q_{i}^{B}=0 \\
& \partial \pi_{i} / \partial q_{i}^{B}=a-b \sum_{i=1}^{n} q_{i}^{B}-b \theta \sum_{i=1}^{n} q_{i}^{A}-l^{B}-l^{C}-c-b q_{i}^{B}-b \theta q_{i}^{A}=0
\end{aligned}
$$


And we can get equilibrium output quantity:

$$
\begin{aligned}
Q_{C d}^{A} & =\frac{n}{n+1} \frac{(a-c)(1-\theta)-l^{A}+\theta l^{B}-(1-\theta) l^{C}}{b\left(1-\theta^{2}\right)} \\
Q_{C d}^{B} & =\frac{n}{n+1} \frac{(a-c)(1-\theta)-l^{B}+\theta l^{A}-(1-\theta) l^{C}}{b\left(1-\theta^{2}\right)}
\end{aligned}
$$

To maximize profit and plug Equation (13) to reaction functions, we can get the patent license fees $l_{C d}^{A}$ of pool A, $l_{C d}^{B}$ of pool $B$ and $l_{C d}^{C}$ of the firm in enterprise cluster $C$ outside pools. They are as follows:

$$
\begin{aligned}
& l_{C d}^{A}=l_{C d}^{B}=\frac{(a-c)(1-\theta)}{3-\theta} \\
& l_{C d}^{C}=\frac{a-c}{3-\theta}
\end{aligned}
$$

At this time, the profits of pool $A$, pool $B$ and the firm in enterprise cluster $C$ outside pools are as follows:

$$
\begin{aligned}
\Pi_{C d}^{A} & =\Pi_{C d}^{B}=\frac{n}{n+1} \frac{1}{b(1+\theta)} \frac{(a-c)^{2}(1-\theta)}{(3-\theta)^{2}} \\
\Pi_{C d}^{C} & =\frac{n}{n+1} \frac{1}{b(1+\theta)} \frac{2(a-c)^{2}}{(3-\theta)^{2}}
\end{aligned}
$$

To compare Formula (15) with Formula (11), we find $\Pi_{C d}^{A}<\Pi^{A}, \Pi_{C d}^{B}<\Pi^{B}$, but the profit of the firm outside pools $\Pi_{C d}^{C}>\Pi_{C d}^{A}+\Pi_{C d}^{B}$.

If a firm in pool $A$ successfully produce the new blocking patent at first, because of Grant-back Clause, the firm have to return the patent right to pool $A$ gratis, because this patent is a blocking patent and it is in pool $A$, if use technical standard in pool $B$ to make terminal product, firm need pay for this patent license fee to pool $A$, then the firm of the first-order condition for maximum value of profit in downstream market is as follows:

$$
\begin{aligned}
& \partial \pi_{i} / \partial q_{i}^{A}=a-b \sum_{i=1}^{n} q_{i}^{A}-b \theta \sum_{i=1}^{n} q_{i}^{B}-l^{A}-c-b q_{i}^{A}-b \theta q_{i}^{B}=0 \\
& \partial \pi_{i} / \partial q_{i}^{B}=a-b \sum_{i=1}^{n} q_{i}^{B}-b \theta \sum_{i=1}^{n} q_{i}^{A}-l^{B}-l^{A}-c-b q_{i}^{B}-b \theta q_{i}^{A}=0
\end{aligned}
$$

And get equilibrium output quantity:

$$
\begin{aligned}
Q_{A d}^{A} & =\frac{n}{n+1} \frac{(a-c)(1-\theta)-(1-\theta) l^{A}+\theta l^{B}}{b\left(1-\theta^{2}\right)} \\
Q_{A d}^{B} & =\frac{n}{n+1} \frac{(a-c)(1-\theta)-l^{B}-(1-\theta) l^{A}}{b\left(1-\theta^{2}\right)}
\end{aligned}
$$

We use first-order derivative of $\Pi_{A d}^{A}=l_{A d}^{A}\left(Q_{A d}^{A}+Q_{A d}^{B}\right)$ and $\Pi_{A d}^{B}=l_{A d}^{B} Q_{A d}^{B}$ to get reaction functions and further we can get the patent license fees $l_{A d}^{A}$ of pool A, $l_{A d}^{B}$ of pool $B$ as follows:

$$
\begin{aligned}
& l_{A d}^{A}=\frac{(a-c)(3+\theta)}{7+\theta} \\
& l_{A d}^{B}=\frac{2(a-c)(1-\theta)}{7+\theta}
\end{aligned}
$$

From above some equations, we can get two pools profits:

$$
\begin{aligned}
\Pi_{A d}^{A} & =\frac{n}{n+1} \frac{1}{b(1+\theta)} \frac{2(a-c)^{2}(3+\theta)^{2}}{(7+\theta)^{2}} \\
\Pi_{A d}^{B} & =\frac{n}{n+1} \frac{1}{b(1+\theta)} \frac{4(a-c)^{2}(1-\theta)}{(7+\theta)^{2}}
\end{aligned}
$$


From Equation (19), we can see $\Pi_{A d}^{A}$ becomes bigger with $\theta$ bigger, however $\Pi_{A d}^{B}$ is completely opposite.

Because the firms in two pools have symmetrical characteristic, if a firm in pool $B$ successfully produce the new blocking patent at first, we can easily write out all kinds of data, as follows:

The patent license fees $l_{B d}^{A}$ of pool B, $l_{B d}^{B}$ of pool $A$ :

$$
\begin{aligned}
& l_{B d}^{B}=\frac{(a-c)(3+\theta)}{7+\theta} \\
& l_{B d}^{A}=\frac{2(a-c)(1-\theta)}{7+\theta}
\end{aligned}
$$

The profits of pool $B$ and pool $A$ respectively are:

$$
\begin{aligned}
& \Pi_{B d}^{B}=\frac{n}{n+1} \frac{1}{b(1+\theta)} \frac{2(a-c)^{2}(3+\theta)^{2}}{(7+\theta)^{2}} \\
& \Pi_{B d}^{A}=\frac{n}{n+1} \frac{1}{b(1+\theta)} \frac{4(a-c)^{2}(1-\theta)}{(7+\theta)^{2}}
\end{aligned}
$$

Now we start to analysis of patent race. Suppose the quantity of firms in pool $A$ is $N^{A}$, a firm $i$ in pool $A$ puts the fund $x_{i}^{A}$ into R\&D a new blocking patent at a period, the expected profit of firm $i$ is $V_{i d}^{A}$. On the other hand, the quantity of firms in pool $B$ is $N^{B}$, a firm $j$ in pool $B$ puts the fund $x_{j}^{B}$ into R\&D a new blocking patent at a period, the expected profit of firm $j$ is $V_{j d}^{B}$. Another aspect, the quantity of firms in enterprise cluster $C$ but outside pools is $N^{C}$, a firm $k$ in enterprise cluster $C$ puts the fund $x_{k}^{C}$ into R\&D a new blocking patent at a period, the expected profit of firm $k$ is $V_{k d}^{C}$, patent race start at time 0 . Firm $i$ in pool $A$ gets profit at the distribution ratio $\mu_{i}^{A}$ (refer to Assumption 3), on the other side firm $j$ in pool $B$ gets profit at the distribution ratio $\mu_{j}^{B}$.

At present, we analyze the expected profit $V_{i}^{A}$ of firm $i$ in pool A. Because the process of R\&D a new patent is a Poisson process at beginning of time 0 , then at the time $t$, the unsuccessful probability of R\&D a new patent is as follows:

$$
\mathrm{e}^{-\left[\sum_{i}^{\left.h h\left(x_{i}^{A}\right)+\sum_{j} h\left(x_{j}^{B}\right)+\sum_{k} h\left(x_{k}^{C}\right)\right] t}\right.}
$$

If there are no firms can successfully $\mathrm{R} \& \mathrm{D}$ the new patent at the time $t$, the profit of firm $i$ from $t$ to $t+\mathrm{d} t$ is:

$$
\left(\mu_{i}^{A} \Pi^{A}-x_{i}^{A}\right) \mathrm{d} t
$$

Suppose discount rate is $r$, the cash flow of a new patent at very period is $V$, then the present value of the profit of a new patent is:

$$
V_{N}=\int_{0}^{\infty} V \mathrm{e}^{-r t} \mathrm{~d} t=\frac{V}{r}
$$

If pool A successfully produces a new patent with probability of $\sum_{i} h\left(x_{i}^{A}\right) \mathrm{d} t$ at first, from this moment, firm $i$ in pool $A$ can get the present value of the profit in very period:

$$
\frac{\mu_{i}^{A} \Pi_{A d}^{A}}{r}
$$

If pool $B$ successfully produces a new patent with probability of $\sum_{j} h\left(x_{j}^{B}\right) \mathrm{d} t$ at first, from this moment, firm $i$ in pool $A$ can get the present value of the profit in very period:

$$
\frac{\mu_{i}^{A} \Pi_{B d}^{A}}{r}
$$


If enterprise cluster $C$ successfully produces a new patent with probability of $\sum_{k} h\left(x_{k}^{C}\right) \mathrm{d} t$ at first, from this moment, firm $i$ in pool $A$ can get the present value of the profit in very period:

$$
\frac{\mu_{i}^{A} \Pi_{C d}^{A}}{r}
$$

From above analysis, we can get the present value function $V_{i d}^{A}\left(x_{1}^{A} \cdots x_{N^{A}}^{A}, x_{1}^{B} \cdots x_{N^{B}}^{B}, x_{1}^{C} \cdots x_{N^{C}}^{C}\right)$ of firm $i$ in pool $A$ is as follows:

$$
\begin{aligned}
V_{i d}^{A} & =\int_{0}^{\infty} \mathrm{e}^{-r t} \mathrm{e}^{-\left[\sum_{i} h\left(x_{i}^{A}\right)+\sum_{j} h\left(x_{j}^{B}\right)+\sum_{k} h\left(x_{k}^{C}\right)\right] t}\left(\mu_{i}^{A} \Pi^{A}-x_{i}^{A}\right)+\sum_{i} h\left(x_{i}^{A}\right) \frac{\mu_{i}^{A} \Pi_{A d}^{A}}{r}+\sum_{j} h\left(x_{j}^{B}\right) \frac{\mu_{i}^{A} \Pi_{B d}^{A}}{r}+\sum_{k} h\left(x_{k}^{C}\right) \frac{\mu_{i}^{A} \Pi_{C d}^{A}}{r} \mathrm{~d} t \\
& =\frac{\mu_{i}^{A} \Pi^{A}-x_{i}^{A}+\sum_{i} h\left(x_{i}^{A}\right) \frac{\mu_{i}^{A} \Pi_{A d}^{A}}{r}+\sum_{j} h\left(x_{j}^{B}\right) \frac{\mu_{i}^{A} \Pi_{B d}^{A}}{r}+\sum_{k} h\left(x_{k}^{C}\right) \frac{\mu_{i}^{A} \Pi_{C d}^{A}}{r}}{\sum_{i} h\left(x_{i}^{A}\right)+\sum_{j} h\left(x_{j}^{B}\right)+\sum_{k} h\left(x_{k}^{C}\right)+r}
\end{aligned}
$$

To maximize $V_{i d}^{A}\left(x_{1}^{A} \cdots x_{N^{A}}^{A}, x_{1}^{B} \cdots x_{N^{B}}^{B}, x_{1}^{C} \cdots x_{N^{C}}^{C}\right)$, we have first order condition: $\partial V_{i d}^{A} / \partial x_{i}^{A}=0$, to maximize $V_{i d}^{A}$ and solve it, we can get:

$$
\begin{gathered}
\left(\Pi_{A d}^{A}-\Pi^{A}\right)+\sum_{j} h\left(x_{j}^{B}\right) \frac{\Pi_{A d}^{A}-\Pi_{B d}^{A}}{r}+\sum_{k} h\left(x_{k}^{C}\right) \frac{\Pi_{A d}^{A}-\Pi_{C d}^{A}}{r} \\
-\frac{\sum_{i} h\left(x_{i}^{A}\right)+\sum_{j} h\left(x_{j}^{B}\right)+\sum_{k} h\left(x_{k}^{C}\right)+r-h^{\prime}\left(x_{i}^{A}\right) x_{i}^{A}}{\mu_{i}^{A} h^{\prime}\left(x_{i}^{A}\right)}=0
\end{gathered}
$$

Proposition 1. In the race of the R\&D a new blocking patent, a firm in a pool will increase (or decrease) the fund of investment in R\&D a new blocking patent as the other firms in the same pool decrease (or increase) the fund of investment in R\&D a new blocking patent. When $\mu_{i}^{A}$ is not too small and $r$ is not too big, a firm in one pool will increase (or decrease) the fund of investment in R\&D a new blocking patent as the firms in the other pool or the firms outside pools increase (or decrease) the fund of investment in R\&D a new blocking patent.

Proof: From comparing Equations (15), (19) and (21), we know former three terms in Equation (28) are all greater than 0 . Now we transform the last items of Equation (28) as follow:

$$
\begin{aligned}
& \frac{\sum_{i} h\left(x_{i}^{A}\right)+\sum_{j} h\left(x_{j}^{B}\right)+\sum_{k} h\left(x_{k}^{C}\right)+r-h^{\prime}\left(x_{i}^{A}\right) x_{i}^{A}}{\mu_{i}^{A} h^{\prime}\left(x_{i}^{A}\right)} \\
& =\frac{\sum_{s \neq i} h\left(x_{s}^{A}\right)+\sum_{j} h\left(x_{j}^{B}\right)+\sum_{k} h\left(x_{k}^{C}\right)+r+h\left(x_{i}^{A}\right)-h^{\prime}\left(x_{i}^{A}\right) x_{i}^{A}}{\mu_{i}^{A} h^{\prime}\left(x_{i}^{A}\right)}
\end{aligned}
$$

Because of $h^{\prime}\left(x_{i}\right)>0, h^{\prime \prime}\left(x_{i}\right)<0, h(0)=0$, we know $h^{\prime}\left(x_{i}^{A}\right)$ is the smaller, the $x_{i}^{A}$ is bigger. For numerator $h\left(x_{i}^{A}\right)-h^{\prime}\left(x_{i}^{A}\right) x_{i}^{A}$, we have Equation (30) as follows:

$$
h\left(x_{i}^{A}\right)-h^{\prime}\left(x_{i}^{A}\right) x_{i}^{A}=x_{i}^{A}\left(\frac{h\left(x_{i}^{A}\right)}{x_{i}^{A}}-h^{\prime}\left(x_{i}^{A}\right)\right)>0
$$

Assumption 6 is used in Equation (30) that $h\left(x_{i}\right)$ is concave function, and we take the derivative of Equation (30) as follows:

$$
\frac{\partial\left[h\left(x_{i}^{A}\right)-h^{\prime}\left(x_{i}^{A}\right) x_{i}^{A}\right]}{\partial x_{i}^{A}}=-h^{\prime \prime}\left(x_{i}^{A}\right) x_{i}^{A}>0
$$


So we can see that $h\left(x_{i}^{A}\right)-h^{\prime}\left(x_{i}^{A}\right) x_{i}^{A}$ is a monotone decreasing function for $x_{i}^{A}$.

If the fund $x_{s}^{A}(s \neq i)$ of investment in R\&D a new patent of another firm $s$ in pool $A$ increase, then $h\left(x_{s}^{A}\right)$ will also increase, however ahead three terms in Equation (28) are all greater than 0 and these three items are uncorrelated with fund $x_{i}^{A}$ of investment in R\&D a new patent of firm $i$ and Equation (28) is equivalent to 0, so the value of Equation (29) will also keep invariant, namely the value of Equation (29) does not change with $x_{i}^{A}$ variation. At this time, if $x_{s}^{A}$ increases, then the value of the first term in Equation (29) will also increase, at the same time the value of Equation (29) keep invariable, according to monotonicity of $h\left(x_{i}^{A}\right)-h^{\prime}\left(x_{i}^{A}\right) x_{i}^{A}, x_{i}^{A}$ must become small.

Above analysis explains that a firm in a pool will increase (or decrease) the fund of investment in R\&D a new blocking patent as the other firms in the same pool decrease (or increase) the fund of investment in R\&D a new blocking patent.

Moreover, when firm $j$ in pool $B$ or firm $k$ in enterprise cluster $C$ (outside pools) decreases the fund of investment in R\&D a new blocking patent, on the basis of Equation (28), only meets inequality (32):

$$
\begin{aligned}
& \mu_{i}^{A} h^{\prime}\left(x_{i}^{A}\right) \frac{\Pi_{A d}^{A}-\Pi_{B d}^{A}}{r}-1>0 \\
& \mu_{i}^{A} h^{\prime}\left(x_{i}^{A}\right) \frac{\Pi_{A d}^{A}-\Pi_{C d}^{A}}{r}-1>0
\end{aligned}
$$

Firm $i$ in pool $A$ will decrease the fund of investment in R\&D a new blocking patent.

On account of Assumption 5 that the firms in two pools have symmetrical characteristic, the status of firm $j$ in pool $B$ is like firm $i$ in pool $A$, we can write out the maximum first-order condition as follows:

$$
\begin{gathered}
\Pi_{B d}^{B}-\Pi^{B}+\sum_{i} h\left(x_{i}^{A}\right) \frac{\Pi_{B d}^{B}-\Pi_{A d}^{B}}{r}+\sum_{k} h\left(x_{k}^{C}\right) \frac{\Pi_{B d}^{B}-\Pi_{C d}^{B}}{r} \\
-\frac{\sum_{i} h\left(x_{i}^{A}\right)+\sum_{j} h\left(x_{j}^{B}\right)+\sum_{k} h\left(x_{k}^{C}\right)+r-h^{\prime}\left(x_{j}^{B}\right) x_{j}^{B}}{\mu_{j}^{b} h^{\prime}\left(x_{j}^{B}\right)}=0
\end{gathered}
$$

Apply the same method of analysis of firm $i$ in pool $A$, we can prove a firm in pool $B$ and a firm in pool $A$ are the same change trend of investment in R\&D a new blocking patent.

So Proposition 1 has been finished proof.

Proposition 1 indicates pool has crowding-out effect on investment in R\&D a new blocking patent of firms in pool. It originates from Grant-back Clause. It results in R\&D responsibility's being disrupt that a firm must gratis give back the new patent right to pool, very firm all hope the other firm finish patent innovation, while it can be free to share the profit from new patent. We also call this behavior free-ride. This behavior will make R\&D investment in pool insufficient.

Proposition 1 is proved in some soft situations, if there do not appear extreme conditions, Proposition 1 will be correct. Nevertheless in extreme conditions, such as $\mu_{i}^{A}$ is too small, $r$ is too big, namely, a firm has too little patents and $R \& D$ risk is too big, when firms outside pools add investment in $R \& D$, on the contrary, the firm in pools will reduce, even give up investment in $R \& D$, because the expected profit of new patent will be estimated very low, even 0 or negative by the firm.

Proposition 2. The more patents a firm in pools owns, bigger fund the firm put in R\&D.

Proof: Because patent quantity proportion $\mu_{i}^{A}$ of a firm in pools is a term of denominator in Equation (29), when $\mu_{i}^{A}$ becomes big, in the meantime, the value of Equation (28) keeps constant, $x_{i}^{A}$ must become big, that is to say the firm must add investment in R\&D.

So Proposition 2 has been finished proof.

Proposition 3. In the race of the R\&D a new blocking patent, when $r$ is not too big, a firm outside pools will increase (or decrease) the fund of investment in R\&D a new blocking patent as other firms in pools increase (or decrease) the fund of investment in R\&D a new blocking patent.

Proof: If a firm $k$ outside pools encounters R\&D failure, its profit will be 0 . On the other hand, if it achieves R\&D success, the firm will be a new incomer in patent race to get profit $\Pi_{C d}^{C}$, according to Equation (15), we can get the expected profit of the firm outside pools as follows: 


$$
\begin{aligned}
V_{k d}^{C} & =\int_{0}^{\infty} \mathrm{e}^{-r t} \mathrm{e}^{-\left[\sum_{i}^{h}\left(x_{i}^{A}\right)+\sum_{j} h\left(x_{j}^{B}\right)+\sum_{k} h\left(x_{k}^{C}\right)\right] t}\left(-x_{k}^{C}+h\left(x_{k}^{C}\right) \frac{\Pi_{C d}^{C}}{r}\right) \mathrm{d} t \\
& =\frac{-x_{k}^{C}+h\left(x_{k}^{C}\right) \frac{\Pi_{C d}^{C}}{r}}{\sum_{i} h\left(x_{i}^{A}\right)+\sum_{j} h\left(x_{j}^{B}\right)+\sum_{k} h\left(x_{k}^{C}\right)+r}
\end{aligned}
$$

We have first order condition: $\partial V_{k d}^{C} / \partial x_{k}^{C}=0$ to maximize $V_{k d}^{C}$ and solve it, we can get:

$$
\begin{aligned}
\Pi_{C d}^{C}+\left(\sum_{s \neq k} h\left(x_{s}^{C}\right)+\sum_{i} h\left(x_{i}^{A}\right)+\sum_{j} h\left(x_{j}^{B}\right)\right) \frac{\Pi_{C d}^{C}}{r} & \sum_{s} h\left(x_{s}^{C}\right)+\sum_{i} h\left(x_{i}^{A}\right)+\sum_{j} h\left(x_{j}^{B}\right)-h^{\prime}\left(x_{k}^{C}\right) x_{k}^{C} \\
h^{\prime}\left(x_{k}^{C}\right) & =0
\end{aligned}
$$

From Equation (35) and applying the same method of proving Proposition 1, we can finish proving Proposition 3.

\subsection{Analysis of Innovation Effect of Improvement Patents}

Suppose there is a chance to $R \& D$ a new improvement patent for pool $A$. We use corner mark s to indicate all variables related to the new improvement patent. After successfully producing a new improvement patent, pool $A$ has stronger competitiveness for pool $B$, namely the differentiation parameter $\theta$ becomes smaller. Suppose the differentiation parameter changes into $\theta^{\prime}\left(\theta^{\prime}<\theta\right)$ because of the new improvement patent being successfully produced. At this case, we call pool $A$ advanced pool and call pool $B$ non-advanced pool.

Although this new improvement patent is for patents in pool $A$, if a firm in pool $B$ or outside pools successfully produces this patent, the firm sells this patent right to pool $A$ to get the patent license fee.

Now we suppose a firm $C$ outside pools successfully produces a new improvement patent for pool $A$. Because pool $A$ is advanced pool, this new patent must be used with patents in pool $A$, firm $C$ has no dominant position of the monopoly pricing, then the new patent license fee is priced by symmetric Nash equilibrium bargaining. So the firm only gets average profit from this new patent.

If a firm $C$ outside pools successfully produces a new improvement patent and sells this new patent to pool $A$ at patent license fee $P_{C s}^{C}$, according to Equation (11) and above assumption and analysis, we can get:

$$
\begin{aligned}
& P_{C s}^{C}=\frac{1}{2}\left[\Pi^{A}\left(\theta^{\prime}\right)-\Pi^{A}(\theta)\right] \\
& P_{C s}^{C}=\frac{1}{2} \frac{n(a-c)^{2}}{(n+1) b}\left[\frac{\left(1-\theta^{\prime}\right)}{\left(2-\theta^{\prime}\right)^{2}\left(1+\theta^{\prime}\right)}-\frac{(1-\theta)}{(2-\theta)^{2}(1+\theta)}\right]
\end{aligned}
$$

The profit of firm $C$ outside pools is $P_{C s}^{C}$ :

$$
\Pi_{C s}^{C}=P_{C s}^{C}
$$

The profit of pool $A$ and pool $B$ is respectively as follows:

$$
\begin{gathered}
\Pi_{C s}^{A}=\Pi^{A}\left(\theta^{\prime}\right)-P_{C s}^{C}=\frac{1}{2} \frac{n(a-c)^{2}}{(n+1) b}\left[\frac{\left(1-\theta^{\prime}\right)}{\left(2-\theta^{\prime}\right)^{2}\left(1+\theta^{\prime}\right)}+\frac{(1-\theta)}{(2-\theta)^{2}(1+\theta)}\right] \\
\Pi_{C s}^{B}=\Pi^{B}\left(\theta^{\prime}\right)=\frac{n}{n+1} \cdot \frac{(a-c)^{2}\left(1-\theta^{\prime}\right)}{\left(2-\theta^{\prime}\right)^{2}\left(1+\theta^{\prime}\right) b}
\end{gathered}
$$

If a firm in pool $A$ successfully produces a new improvement patent, because of Grant-back Clause, the profit of pool $A$ and pool $B$ is respectively as follows: 


$$
\Pi_{A s}^{A}=\Pi_{A s}^{B}=\frac{n}{n+1} \cdot \frac{(a-c)^{2}\left(1-\theta^{\prime}\right)}{\left(2-\theta^{\prime}\right)^{2}\left(1+\theta^{\prime}\right) b}
$$

If a firm in pool $B$ successfully produces a new improvement patent for pool $A$, because pool $A$ is advanced pool, this new patent must be used with patents in pool $A$, the firm in pool $B$ sells this new patent to pool $A$ at patent license fee $P_{B s}^{B}$, then we can get as follows:

$$
P_{B s}^{B}=\frac{1}{2}\left[\Pi^{A}\left(\theta^{\prime}\right)-\Pi^{A}(\theta)\right]=\frac{1}{2} \frac{n(a-c)^{2}}{(n+1) b}\left[\frac{\left(1-\theta^{\prime}\right)}{\left(2-\theta^{\prime}\right)^{2}\left(1+\theta^{\prime}\right)}-\frac{(1-\theta)}{(2-\theta)^{2}(1+\theta)}\right]
$$

From above equations, we can see $P_{B s}^{B}=P_{C S}^{C}$, so we take $P_{s}=P_{B s}^{B}=P_{C s}^{C}$.

At this moment, the profit of pool $A$ and pool $B$ is respectively as follows:

$$
\begin{aligned}
\Pi_{B S}^{A}=\Pi^{A}\left(\theta^{\prime}\right)-P_{B S}^{B} & =\frac{1}{2} \frac{n(a-c)^{2}}{(n+1) b}\left[\frac{\left(1-\theta^{\prime}\right)}{\left(2-\theta^{\prime}\right)^{2}\left(1+\theta^{\prime}\right)}+\frac{(1-\theta)}{(2-\theta)^{2}(1+\theta)}\right] \\
\Pi_{B S}^{B} & =\Pi^{B}\left(\theta^{\prime}\right)=\frac{n}{n+1} \cdot \frac{(a-c)^{2}\left(1-\theta^{\prime}\right)}{\left(2-\theta^{\prime}\right)^{2}\left(1+\theta^{\prime}\right) b}
\end{aligned}
$$

From above equations, we can see $\Pi_{B s}^{A}=\Pi_{C s}^{A}$.

Now we analyze patent race. Suppose the quantity of firms in pool $A$ is $N^{A}$, a firm $i$ in pool $A$ puts the fund $x_{i}^{A}$ into R\&D a new improvement patent at a period, the expected profit of firm $i$ is $V_{i s}^{A}$. On the other hand, the quantity of firms in pool $B$ is $N^{B}$, a firm $j$ in pool $B$ puts the fund $x_{j}^{B}$ into R\&D a new improvement patent at a period, the expected profit of firm $j$ is $V_{j s}^{B}$. Another aspect, the quantity of firms in enterprise cluster $C$ but outside pools is $N^{C}$, a firm $k$ in enterprise cluster $C$ puts the fund $x_{k}^{C}$ into R\&D a new improvement patent at a period, the expected profit of firm $k$ is $V_{k s}^{C}$, patent race start at time 0 . Firm $i$ in pool $A$ gets profit at the distribution ratio $\mu_{i}^{\mathrm{A}}$ (refer to Assumption 3), on the other side firm $j$ in pool $B$ gets profit at the distribution ratio $\mu_{j}^{B}$.

Proposition 4. The bigger differentiation a new improvement patent brings about, the more fund of investment in R\&D a firm in advanced pool puts.

Proof: Because the investment of firm's R\&D is a "Poisson Process" of "no memory" of patent race, a new improvement patent brings the present value of expected profit $V_{i s}^{A}$ to firm $i$ in pool $A$ as follow:

$$
V_{i s}^{A}=\frac{\mu_{i}^{A} \Pi^{A}-x_{i}^{A}+\sum_{i} h\left(x_{i}^{A}\right) \frac{\mu_{i}^{A} \Pi_{A S}^{A}}{r}+\sum_{j} h\left(x_{j}^{B}\right) \frac{\mu_{i}^{A} \Pi_{B S}^{A}}{r}+\sum_{k} h\left(x_{k}^{C}\right) \frac{\mu_{i}^{A} \Pi_{B S}^{A}}{r}}{\sum_{i} h\left(x_{i}^{A}\right)+\sum_{j} h\left(x_{j}^{B}\right)+\sum_{k} h\left(x_{k}^{C}\right)+r}
$$

To maximize $V_{\text {is }}^{A}$, the first-order derivative of $V_{i s}^{A}$ equal to zero, we can get as follows:

$$
\begin{aligned}
& 2 \mu_{i}^{A} P_{s}+\mu_{i}^{A}\left(\sum_{j} h\left(x_{j}^{B}\right)+\sum_{k} h\left(x_{k}^{C}\right)\right) \frac{P_{s}}{r} \\
& -\frac{\sum_{i} h\left(x_{i}^{A}\right)+\sum_{j} h\left(x_{j}^{B}\right)+\sum_{k} h\left(x_{k}^{C}\right)+r-h^{\prime}\left(x_{i}^{A}\right) x_{i}^{A}}{h^{\prime}\left(x_{i}^{A}\right)}=0
\end{aligned}
$$

From Equation (45) and applying the same method of proving Proposition 1, we can finish proving Proposition 4.

If pool $B$ is advanced pool, because of two pools' having symmetrical characteristic, we can deduce the same conclusion like Proposition 4.

Proposition 5. In the race of R\&D new improvement patents, If the quantity of patents owned by a firm in advanced pool is similar to the quantity of patents owned by a firm in non-advanced pool, the firm in non-advanced pool will put more fund in R\&D than advanced pool.

Proof: from Equation (41), we can see $P_{s}$ becomes bigger with $\theta^{\prime}$ decreasing. And from Equation (45), we can know firm $i$ in pool $A$ will increase investment in R\&D with $\theta^{\prime}$ decreasing. Then for firm $j$ in pool $B$, the 
present value of expected profit $V_{j s}^{B}$ is as follow:

$$
V_{j s}^{B}=\frac{\mu_{j}^{B} \Pi^{B}-x_{j}^{B}+h\left(x_{j}^{B}\right) \frac{\mu_{j}^{B} \Pi_{s}^{B}+P_{s}}{r}+\left(\sum_{u \neq j} h\left(x_{u}^{B}\right)+\sum_{j} h\left(x_{i}^{A}\right)+\sum_{k} h\left(x_{k}^{C}\right)\right) \frac{\mu_{j}^{B} \Pi_{s}^{B}}{r}}{\sum_{i} h\left(x_{i}^{A}\right)+\sum_{j} h\left(x_{j}^{B}\right)+\sum_{k} h\left(x_{k}^{C}\right)+r}
$$

Because of $\Pi_{s}^{B}=\Pi_{A s}^{B}=\Pi_{B s}^{B}=\Pi_{C s}^{B}$.

To maximize $V_{j s}^{B}$, the first-order derivative of $V_{j s}^{B}$ equal to zero, we can get as follow:

$$
\begin{gathered}
\left(2 \mu_{j}^{B}+1\right) P_{s}+\left(\sum_{u \neq j} h\left(x_{u}^{B}\right)+\sum_{i} h\left(x_{i}^{A}\right)+\sum_{k} h\left(x_{k}^{C}\right)\right) \frac{P_{s}}{r} \\
-\frac{\sum_{i} h\left(x_{i}^{A}\right)+\sum_{u} h\left(x_{u}^{B}\right)+\sum_{k} h\left(x_{k}^{C}\right)+r-h^{\prime}\left(x_{j}^{B}\right) x_{j}^{B}}{h^{\prime}\left(x_{j}^{B}\right)}=0
\end{gathered}
$$

From Equation (47) and applying the same method of proving Proposition 1, we can finish proving Proposition 5.

Proposition 6. In the race of R\&D new improvement patents, a firm in one pool is more willing to R\&D new improvement patents for the other pool than for own pool.

Proof: To compare Equation (45) with (47), when $\mu_{i}^{A}$ is not too different from $\mu_{j}^{B}$, the sum of former two terms in Equation (47) is greater than the sum of former two terms in Equation (45), then in order to keep Equation (47) still at 0 , the $x_{j}^{B}$ must become big, that is, firm $j$ have to put more fund into $R \& D$. So we can get Proposition 6.

If pool $B$ is advanced pool, because of two pools' having symmetrical characteristic, we can deduce the same conclusion like Proposition 6.

So Proposition 2 has been finished proof.

Proposition 7. In the race of R\&D new improvement patents, If the quantity of patents owned by a firm in advanced pool is similar to the quantity of patents owned by a firm in non-advanced pool, the firm in non-advanced pool will put most fund in R\&D, the firm outside pools put middle, the firm in advanced pool put least.

Proof: Now we can write out the present value of expected profit $V_{k s}^{C}$ as follow:

$$
V_{k s}^{C}=\frac{-x_{k}^{C}+h\left(x_{k}^{C}\right) \frac{P_{s}}{r}}{\sum_{i} h\left(x_{i}^{A}\right)+\sum_{j} h\left(x_{j}^{B}\right)+\sum_{u} h\left(x_{u}^{C}\right)+r}
$$

To maximize $V_{k s}^{C}$, the first-order derivative of $V_{k s}^{C}$ equal to zero, we can get as follows:

$$
\begin{aligned}
& P_{s}+\left(\sum_{i} h\left(x_{i}^{A}\right)+\sum_{j} h\left(x_{j}^{B}\right)+\sum_{u \neq k} h\left(x_{u}^{C}\right)\right) \frac{P_{s}}{r} \\
& -\frac{\sum_{i} h\left(x_{i}^{A}\right)+\sum_{j} h\left(x_{j}^{B}\right)+\sum_{u} h\left(x_{u}^{C}\right)+r-h^{\prime}\left(x_{k}^{C}\right) x_{k}^{C}}{h^{\prime}\left(x_{k}^{C}\right)}=0
\end{aligned}
$$

Compare and analyze Equation (45), (47) and (49), we can get Proposition 7.

\subsection{Analysis of Innovation Effect of Additional Innovation Patents}

Suppose there is a chance to a new additional innovation patent, this new can reduce the cost of terminal product production, we use corner mark $o$ to indicate all variables related to the new additional innovation patent, if this new patent is applied in terminal product production, the cost $c$ of product production will lower to $c^{\prime} \quad\left(c^{\prime}<c\right)$. At this moment, firms in pools and outside pools all want to R\&D this new patent.

Because this patent can reduce the cost of terminal product production, if this patent license fee is acceptable, firms who produce terminal products in downstream-market are willing to purchase this patent right. 
Because this new patent is not in pools, a firm who owns this patent does not have dominant position of the monopoly pricing, so the new patent license fee is priced by symmetric Nash equilibrium bargaining, namely the firm only gets average profit from this new patent.

If a firm $k$ outside pools successfully produces a new additional innovation patent and sells this new patent to the firms who produce terminal products in downstream-market at patent license fee $P_{C o}^{C}$, then we can get as follows:

$$
\Pi_{C_{o}}^{C}=P_{C o}^{C}=\frac{1}{2} n\left[\pi\left(c^{\prime}\right)-\pi(c)\right]=\frac{n\left[\left(a-c^{\prime}\right)^{2}-(a-c)^{2}\right]}{(n+1)^{2}(2-\theta)^{2}(1+\theta) b}
$$

From above Equation (50), the lower cost $c^{\prime}$, the higher patent license fee $P_{C o}^{C}$ is, that is, the higher the profit $\Pi_{C o}^{C}$ of the firm $k$ is.

After the firm $k$ outside pools successfully produces a new additional innovation patent, sell this new patent to the firms who produce terminal products in downstream-market at patent license fee $P_{C o}^{C}$, then the profit $\Pi_{C o}^{A}$ of pool $A$ and the profit $\Pi_{C o}^{B}$ of pool $B$ are the same as follows:

$$
\Pi_{C o}^{A}=\Pi_{C o}^{B}=\frac{n}{n+1} \cdot \frac{\left(a-c^{\prime}\right)^{2}(1-\theta)}{(2-\theta)^{2}(1+\theta) b}
$$

If a firm $i$ in pool $A$ successfully produces a new additional innovation patent and sells this new patent to the firms who produce terminal products in downstream-market at patent license fee $P_{A o}^{A}$, then $P_{A o}^{A}$ is as follows:

$$
P_{A o}^{A}=P_{C o}^{C}=\frac{n\left[\left(a-c^{\prime}\right)^{2}-(a-c)^{2}\right]}{(n+1)^{2}(2-\theta)^{2}(1+\theta) b}
$$

The profit of pool $A$ and pool $B$ as follows:

$$
\Pi_{A o}^{A}=\Pi_{A o}^{B}=\frac{n}{n+1} \cdot \frac{\left(a-c^{\prime}\right)^{2}(1-\theta)}{(2-\theta)^{2}(1+\theta) b}
$$

Because the firms in two pools have symmetrical characteristic, if a firm $j$ in pool $B$ successfully produces a new additional innovation patent and sells this new patent to the firms who produce terminal products in downstream-market at patent license fee $P_{B o}^{B}$, we can write out the equations about $P_{B o}^{B}, \Pi_{B o}^{A}$ and $\Pi_{B o}^{B}$.

Because a new additional innovation patent is independently applied in products production, it are not restrained by Grant-back Clause and they are not recruited in pools, even though a firm in pools successfully produces a new additional innovation patent, the new patent right is only owned by the firm rather than pools, consequently the patent license fee is gotten by the firm rather than pools.

By means of above analysis, we can know, no matter what in cases, the patent license fee is the same, and the profits of two pools are the same. In order to facilitate analysis, we define the patent license fee as $P_{o}$, the profit of two pools as $\Pi_{o}$, then we can get as follows:

$$
P_{o}=P_{A o}^{A}=P_{B o}^{B}=P_{C o}^{C}, \Pi_{o}=\Pi_{A o}^{A}=\Pi_{A o}^{B}=\Pi_{B o}^{A}=\Pi_{B o}^{B} .
$$

Now we analyze patent race. Suppose the quantity of firms in pool $A$ is $N^{A}$, a firm $i$ in pool $A$ puts the fund $x_{i}^{A}$ into R\&D a new additional innovation patent at a period, the expected profit of firm $i$ is $V_{i o}^{A}$. On the other hand, the quantity of firms in pool $B$ is $N^{B}$, a firm $j$ in pool $B$ puts the fund $x_{j}^{B}$ into R\&D a new additional innovation patent at a period, the expected profit of firm $j$ is $V_{j o}^{B}$. Another aspect, the quantity of firms in enterprise cluster $C$ but outside pools is $N^{C}$, a firm $k$ in enterprise cluster $C$ puts the fund $x_{k}^{C}$ into R\&D a new additional innovation patent at a period, the expected profit of firm $k$ is $V_{k o}^{C}$, patent race start at time 0 . Firm $i$ in pool $A$ gets profit at the distribution ratio $\mu_{i}^{A}$ (refer to Assumption 3), on the other side firm $j$ in pool $B$ gets profit at the distribution ratio $\mu_{j}^{B}$.

Proposition 8. In the R\&D race of a new additional innovation patent, the firms in pools are more willing to R\&D a new patent than the firms outside pools.

Proof: Because the investment of firm’s R\&D is a "Poisson Process" of "no memory" of patent race, a new additional innovation patent brings the present value of expected profit $V_{i o}^{A}$ to firm $i$ in pool $A$ as follow: 


$$
V_{i o}^{A}=\frac{\mu_{i}^{A} \Pi^{A}-x_{i}^{A}+h\left(x_{i}^{A}\right) \frac{\mu_{i}^{A} \Pi_{o}+P_{o}}{r}+\left[\sum_{u \neq i} h\left(x_{u}^{A}\right)+\sum_{j} h\left(x_{j}^{B}\right)+\sum_{k} h\left(x_{k}^{C}\right)\right] \frac{\mu_{i}^{A} \Pi_{o}}{r}}{\sum_{u} h\left(x_{u}^{A}\right)+\sum_{j} h\left(x_{j}^{B}\right)+\sum_{k} h\left(x_{k}^{C}\right)+r}
$$

To maximize $V_{i o}^{A}$, the first-order derivative of $V_{i o}^{A}$ equal to zero, we can get as follow:

$$
\begin{aligned}
& {\left[\mu_{i}^{A}(n+1)(1-\theta)+1\right] P_{o}+\left(\sum_{u \neq i} h\left(x_{u}^{A}\right)+\sum_{j} h\left(x_{j}^{B}\right)+\sum_{k} h\left(x_{k}^{C}\right)\right) \frac{P_{o}}{r}} \\
& -\frac{\sum_{u} h\left(x_{u}^{A}\right)+\sum_{j} h\left(x_{j}^{B}\right)+\sum_{k} h\left(x_{k}^{C}\right)+r-h^{\prime}\left(x_{i}^{A}\right) x_{i}^{A}}{h^{\prime}\left(x_{i}^{A}\right)}=0
\end{aligned}
$$

If a firm $j$ in pool $B$ successfully produces a new additional innovation patent, because of two patent pools having symmetrical characteristic, the present value of expected profit $V_{j o}^{B}$ of firm $j$ has the same form like $V_{i o}^{A}$ and the first-order derivative of $V_{i o}^{A}$

If a firm $k$ outside pools successfully produces a new additional innovation patent, we also can easily get the present value of expected profit $V_{k o}^{C}$ of firm $k$ as follows:

$$
V_{k o}^{C}=\frac{-x_{k}^{C}+h\left(x_{k}^{C}\right) \frac{P_{o}}{r}}{\sum_{i} h\left(x_{i}^{A}\right)+\sum_{j} h\left(x_{j}^{B}\right)+\sum_{u} h\left(x_{u}^{C}\right)+r}
$$

To maximize $V_{k o}^{C}$, the first-order derivative of $V_{k o}^{C}$ equal to zero, we can get as follow:

$$
\begin{aligned}
& P_{o}+\left(\sum_{i} h\left(x_{i}^{A}\right)+\sum_{j} h\left(x_{j}^{B}\right)+\sum_{u \neq k} h\left(x_{u}^{C}\right)\right) \frac{P_{o}}{r} \\
& -\frac{\sum_{i} h\left(x_{i}^{A}\right)+\sum_{j} h\left(x_{j}^{B}\right)+\sum_{u} h\left(x_{u}^{C}\right)+r-h^{\prime}\left(x_{k}^{C}\right) x_{k}^{C}}{h^{\prime}\left(x_{k}^{C}\right)}=0
\end{aligned}
$$

Compare and analyze Equations (55) with (57), with the help of applying the same method of proving Proposition 6, we can finish proving Proposition 8.

\section{Conclusions}

In this paper, we used classical "Poisson Process" of "no memory" of patent race to develop a model of cumulative innovation effect of competitive patent pools based on different technical standards. This research shows: investment in R\&D of enterprises is a game behavior in the case that there are competitive patent pools in an industry, how much fund a firms puts in R\&D is impacted by competitors' putting in R\&D, at the same time, it impacts investment in $R \& D$ of a firm what pools regulations are and which the relationship type of new patent to be produced with old patents in pools is and whether a firm is in pools or not. However firms all trend towards adding their investment in R\&D for a new patent license fee, that is to say, competitive patent pools is helpful for an industry to innovate.

This research achieves some innovations that are: (ii) We have introduced competitive factors into research of patent pools; (ii) We have introduced the relationship types of new patents with old patents into research of patent pools; (iii) We have studied on innovation effect of enterprise cluster outside pools

Nevertheless this research has some limitations that are: (i) This theoretical model is dynamic games of complete information, yet patent pools often operate in incomplete information in reality; (ii) We have applied the assumption that the firms in two pools have symmetrical characteristic into this research, but every firm has its own distinct characteristics in reality, that is, the firms are all not the same; (iii) We have only studied the case that pools are in longitudinal separation market (an industry is composed of two markets, one is a market of patents R\&D and patents license, and this market is in upstream, the other is a market of terminal products sales and production, and this market is in downstream), now there are some patent pools do not only produce new 
patents but also terminal product, actually for these patent pools, market is a vertical integration.

\section{Support}

This paper and research are funded by National Natural Science Foundation of China, Grant Number: 71373137, Project Title: Study on the standardization of mechanism of effect on initiative innovation and industry development as well as relevant public policy and China Postdoctoral Science Foundation, Grant Number: 2015M581127, Project Title: Study on the formation and governance of technical standard based on the patent pools.

\section{References}

[1] Lerner, J. and Tirole, J. (2004) Efficient Patent Pools. American Economic Review, 94, 691-711.

[2] Shapiro, C. (2001) Navigating the Patent Thicket: Cross Licenses, Patent Pools, and Standard Setting. Innovation Policy and the Economy, 1, 119-150.

[3] Deepak, S. and Daved, J. (2001) Combining Patented Inventions in Multi-Invention Products: Transactional Challenges and Organization Choices. Working Paper [Online]. http://emlab.berkeley.edu/users/bhhall/ipconf/SomayaTeece.pdf

[4] Brenner, S. (2009) Optimal Formation Rules for Patent Pools. Economic Theory, 40, 373-388. http://dx.doi.org/10.1007/s00199-008-0379-z

[5] Kim, S.H. (2004) Vertical Structure and Patent Pools. Review of Industrial Organization, 25, 231-250. http://dx.doi.org/10.1007/s11151-004-3535-Z

[6] Schmidt, K.M. (2008) Complementary Patents and Market Structure. Working Paper [Online]. http://papers.ssrn.com/sol3/papers.cfm?abstract_id=1311129 http://dx.doi.org/10.2139/ssrn.1277948

[7] Kato, A. (2004) Patent Pool Enhances Market Competition. International Review of Law and Economics, 24, $255-268$. http://dx.doi.org/10.1016/j.irle.2004.08.010

[8] Brenner, S. (2004) Stable Patent Pools. Working Paper [Online]. http://scholar.google.co.uk/scholar?q=Stable+patent+pools\&btnG=\&hl=en\&as_sdt=0\%2C5

[9] Denicolo, V. (2000) Two-Stage Patent Races and Patent Policy. Rand Journal of Economics, 31, 488-501. http://dx.doi.org/10.2307/2600997

[10] Denicolo, V. (2002) Sequential Innovation and the Patent Antitrust Conflict. Oxford Economic Papers, 54, 649-668. http://dx.doi.org/10.1093/oep/54.4.649

[11] Hunt, R.M. (2006) When Do More Patents Reduce R\&D. Working Paper [Online]. http://law.bepress.com/cgi/viewcontent.cgi?article=1863\&context=alea

[12] Dequiedt, V. and Versaevel, B. (2007) Patent Pools and the Dynamic Incentives to R\&D. Working Paper [Online]. http://ideas.repec.org/p/gat/wpaper/0703.html

[13] Gilbert, R. (2004) Antitrust for Patent Pools: A Century of Policy Evolution. Stanford Technology Law Review, 3, 149.

[14] Layne, F.A. and Lerner, J. (2008) To Join or Not to Join: Examining Patent Pool Participation and Rent Sharing Rules. International Journal of Industrial Organization, 29, 294-303.

[15] Lee, T. and Wilde, L. (1980) Market Structure and Innovation: a Reformulation. Quarterly Journal of Economics, 94, 429-436. http://dx.doi.org/10.2307/1884551

[16] Lerner, J., Strojwas, M. and Tirole, J. (2007) The Design of Patent Pools: The Determinants of Licensing Rules. Rand Journal of Economics, 38, 610-625. http://dx.doi.org/10.1111/j.0741-6261.2007.00103.x 


\section{Submit or recommend next manuscript to SCIRP and we will provide best service for you:}

Accepting pre-submission inquiries through Email, Facebook, Linkedin, Twitter, etc A wide selection of journals (inclusive of 9 subjects, more than 200 journals)

Providing a 24-hour high-quality service

User-friendly online submission system

Fair and swift peer-review system

Efficient typesetting and proofreading procedure

Display of the result of downloads and visits, as well as the number of cited articles

Maximum dissemination of your research work

Submit your manuscript at: http://papersubmission.scirp.org/ 